\title{
Influence of heterotopic ossification of the hip on bone densitometry: a study in spinal cord injured patients
}

\author{
S Jaovisidha ${ }^{1,2}$, DJ Sartoris ${ }^{1}$, EME Martin ${ }^{3}$, K Foldes ${ }^{1}$, SM Szollar $^{4}$ and LJ Deftos ${ }^{3}$ \\ ${ }^{1}$ Department of Radiology, Section of Osteoradiology, Veterans Affairs Medical Center and the University of \\ California San Diego, 3350 La Jolla Village Drive, San Diego, California 92161, USA; ${ }^{2}$ Department of Radiology, \\ Ramathibodi Hospital, Mahidol University, Bangkok, Thailand; ${ }^{3}$ Department of Medicine, Veterans Affairs Medical \\ Center and the University of California San Diego, San Diego, California, USA; ${ }^{4}$ Department of Orthopedic \\ Rehabilitation-Spinal Injury Unit, Veterans Affairs Medical Center and the University of California San Diego, San \\ Diego, California, USA
}

\begin{abstract}
Objective: To evaluate (1) the magnitude of falsely elevated bone density results caused by heterotopic ossification (HO) around the hip and (2) effect of age of patients when the measurement was taken, age of patients at injury, and age of injury (time since event) to the prevalence of $\mathrm{HO}$.

Subjects and methods: We blindly analyzed plain radiographs of the hip [(obtained within 1 month of dual energy X-ray absorptiometry (DEXA)] in 107 spinal cord injured (SCI) patients for $\mathrm{HO}$ and matched the result to the three regions of interest (ROI): the femoral neck, Ward's triangle, and the trochanter. The influence of HO on bone densitometric values was determined by the analysis of variance (ANOVA) and post-hoc analysis.

Results: Nineteen (18\%) patients had HO; overlying the femoral neck $(79 \%)$, trochanter $(74 \%)$ and Ward's triangle $(37 \%)$, respectively. Significant elevation of densitometric values $(P<0.05$ or less) was observed in a various magnitude at each ROI, with the greatest elevation at Ward's triangle. The prevalence of $\mathrm{HO}$ was high when the patients were injured at age range of $20-39$ years.

Conclusions: HO around the hip can cause significantly elevated bone densitometry results at all ROIs, which can obscure underlying osteoporosis, leading to underestimation of fracture risk. Determination of bone density in this region with corresponding plain radiographs would be of help. In SCI patients, prevalence of HO was high when the age of patients at injury was $20-39$ years.
\end{abstract}

Keywords: hip; abnormalities; ossification; bone; densitometry; absorptiometry

\section{Introduction}

Bone densitometry has a unique and invaluable place in the prevention, diagnosis, and management of osteoporosis. ${ }^{1}$ Dual-energy X-ray absorptiometry (DEXA) represents a major advance in non-invasive, precise measurement of total bone mass (TBM) and bone mineral density (BMD) in selected regions of the body, ${ }^{2,3}$ and is currently considered the bone densitometric technique of choice. ${ }^{1,4}$ With this method, patients at risk of osteoporosis can be identified and the relative risk of fracture can be predicted, leading to proper prevention and early treatment.

Spinal cord injury (SCI) has been noted to commonly cause disuse osteoporosis. ${ }^{3,5-7}$ The pattern of highly selective bone loss from the hip appears to be unique for SCI patients compared to other endocrine causes of osteoporosis, ${ }^{6}$ rendering the hip the most

Correspondence: S Jaovisidha, 224/2 Sukumvit 49-12, Bangkok 10110, Thailand vulnerable site for fracture in this group of patients. Unfortunately, spinal cord injury, as well as other neuromuscular disorders, not only results in osteoporosis, but also induces multi-variable patterns of osseous, articular, and soft tissue alterations. ${ }^{5}$ Heterotopic ossification (HO) is one of these abnormalities that most commonly involves the hip, ${ }^{8-11}$ and it can cause falsely elevated bone densitometric values resulting in a failure to recognize osteoporosis and a misleading estimation of fracture risk. This phenomenon led us to investigate the magnitude and significance of falsely elevated bone density results caused by $\mathrm{HO}$ around the hip using a substantial number of patients, which to our knowledge, has not been previously studied.

\section{Materials and methods}

Laboratory studies including complete blood count (CBC) with differential, erythrocyte sedimentation rate 
(ESR), electrolytes, liver and renal function studies, standard X-rays and bone densitometry were performed on 320 consecutive male patients with spinal cord injuries who were admitted to the spinal cord injury unit at the Veteran Affairs Medical Center from 1994 to 1995 . The patient population included new patients with acute injuries as well as patients who were readmitted for various medical reasons. The inclusion criteria were the subjects who had (1) normal laboratory findings, (2) no clinically obvious indications of heterotopic ossification, (3) no metabolic diseases or other conditions known to influence their calcium metabolism or bone densitometry, and (4) not received treatment influencing these parameters.

One hundred and thirty-five spinal cord-injured subjects (age range 20-78 years, mean age $=48.8 \pm 15.1 \quad$ years, standard error of the mean $=1.3$ years) met these criteria. Sixty-nine ablebodied individuals (age range 24-76 years, mean age $=51.1 \pm 14.1 \quad$ years, standard error of the mean $=1.7$ years) age matched to the 135 subjects were also included in the study. Bone mineral density measurement $\left(\mathrm{g} / \mathrm{cm}^{2}\right)$ of the lumbar spine $(\mathrm{L} 1-\mathrm{L} 4)$ and three regions of the proximal femur (the femoral neck, Ward's triangle and the trochanteric region) were obtained using dual energy X-ray absorptiometry (DEXA) (LUNAR Model DPX; LUNAR Corp., Madison, WI). The DEXA results were interpreted blindly without information of radiographic findings. The data of able-bodied individuals (age-matched controls) was presented elsewhere. ${ }^{12}$

The patients' plain radiographs, which included the hips and were obtained within 1 month of the DEXA studies, were blindly reviewed by three musculoskeletal radiologists who came to consensus agreement without information of DEXA. The results were recorded separately for each region (the femoral neck, Ward's triangle and the trochanteric region) as non-HO or
HO. The radiographic criteria of $\mathrm{HO}$ was an initially poorly defined periarticular radiodense area that do not contain recognizable trabeculae. When the collections enlarge, they merge with the underlying bone in the form of irregular excrescence, and demonstrating trabecular architecture. ${ }^{5}$

For the 135 patients, the proximal femoral bone densitometry was not performed in three patients, plain radiographs which included the hips were not available in 23 patients, and the hip prostheses were observed in two patients, thus excluding them from the study. Of the remaining 107 studied patients, six patients did not have densitometry of the trochanteric regions due to hip contracture from previous surgery which rendered proper positioning unobtainable.

The results of the plain radiographs were then matched to the three regions of interest (ROI) of the DEXA: the femoral neck, Ward's triangle, and the trochanteric region. The effect of $\mathrm{HO}$ on bone densitometric values (bone mineral content (BMCgrams), bone mineral density (BMD - $\mathrm{g} / \mathrm{cm}^{2}$ ) and percentage of BMD compared to age-matched controls was evaluated. The statistical analysis was conducted using Analysis of Variance (ANOVA) followed by a post-hoc analysis using Tukey's honest significant difference (HSD) test to determine (1) the magnitude of false elevation of bone density results due to $\mathrm{HO}$ when the data was stratified by patient, and (2) the magnitude of false elevation of bone density results due to HO when the data was stratified by ROI.

The patients who had HO by plain radiographs were grouped in different categories: grouped by age of patients when the DEXA was taken (patients' present age), by age of injury (time since event) and by age of patients at the time of injury, to see whether or not there was effect of these factors to the prevalence of HO.

Table 1 Mean densitometry and percentage (in brackets) of elevated values of three ROIs of the hip

\begin{tabular}{|c|c|c|c|c|}
\hline & & $\begin{array}{c}B M C \\
\text { (gram) }\end{array}$ & $\begin{array}{c}B M D \\
\left(\mathrm{gm} / \mathrm{cm}^{2}\right)\end{array}$ & $\begin{array}{l}\% B M D \\
\text { compared to } \\
\text { age matched }\end{array}$ \\
\hline \multicolumn{5}{|l|}{ Femoral neck } \\
\hline All studied patients & $(n=107)$ & $4.50 \pm 0.18$ & $0.83 \pm 0.02$ & $82 \pm 2$ \\
\hline Patients without $\mathrm{HO}$ & $(n=92)$ & $4.33 \pm 0.17$ & $0.81 \pm 0.03$ & $81 \pm 3$ \\
\hline Patients with HO & $(n=15)$ & $5.58 \pm 0.68(29 \%)^{\mathrm{a}}$ & $0.91 \pm 0.07$ & $92 \pm 8$ \\
\hline \multicolumn{5}{|l|}{ Ward's triangle } \\
\hline All studied patients & $(n=107)$ & $2.41 \pm 0.14$ & $0.78 \pm 0.06$ & $84 \pm 3$ \\
\hline Patients without $\mathrm{HO}$ & $(n=100)$ & $2.27 \pm 0.12$ & $0.76 \pm 0.06$ & $82 \pm 3$ \\
\hline Patients with $\mathrm{HO}$ & $(n=7)$ & $\begin{array}{l}4.56 \pm 1.17(101 \%)^{\mathrm{b}} \\
\text { and }(89 \%)^{\mathrm{d}}\end{array}$ & $0.98 \pm 0.11$ & $\begin{array}{c}117 \pm 14(43 \%)^{\mathrm{a}} \\
\text { and }(39 \%)^{\mathrm{c}}\end{array}$ \\
\hline \multicolumn{5}{|l|}{ Trochanter } \\
\hline All studied patients & $(n=101)$ & $11.59 \pm 0.57$ & $0.74 \pm 0.02$ & $81 \pm 2$ \\
\hline Patients without $\mathrm{HO}$ & $(n=87)$ & $10.92 \pm 0.51$ & $0.72 \pm 0.02$ & $79 \pm 2$ \\
\hline Patients with $\mathrm{HO}$ & $(n=14)$ & $\begin{array}{l}15.67 \pm 2.49(43 \%)^{\mathrm{a}} \\
\text { and }(35 \%)^{\mathrm{c}}\end{array}$ & $0.86 \pm 0.08(21 \%)^{\mathrm{a}}$ & $94 \pm 9$ \\
\hline
\end{tabular}

${ }^{\mathrm{a}}=$ compared to patients without $\mathrm{HO} ; P<0.05 .{ }^{\mathrm{b}}=$ compared to patients without $\mathrm{HO} ; P<0.001 .{ }^{\mathrm{c}}=$ compared to all studied patients; $P<0.05$. $^{\mathrm{d}}=$ compared to all studied patients; $P<0.001$ 


\section{Results}

Of the 107 subjects, heterotopic ossification (HO) was present in 19 patients $(18 \%)$ : two patients had HO only overlying the femoral neck regions, three had HO overlying the femoral necks and Ward's triangles, six had $\mathrm{HO}$ overlying the femoral necks and trochanteric regions, four had $\mathrm{HO}$ only overlying the trochanteric regions, and four had $\mathrm{HO}$ overlying all three regions. Of these 19 patients, HO was seen overlying the femoral necks in 15 patients $(79 \%)$, trochanteric regions in 14 patients $(74 \%)$ and Ward's triangles in seven patients $(37 \%)$. All of these 19 patients had normal alkaline phosphatase from laboratory studies.

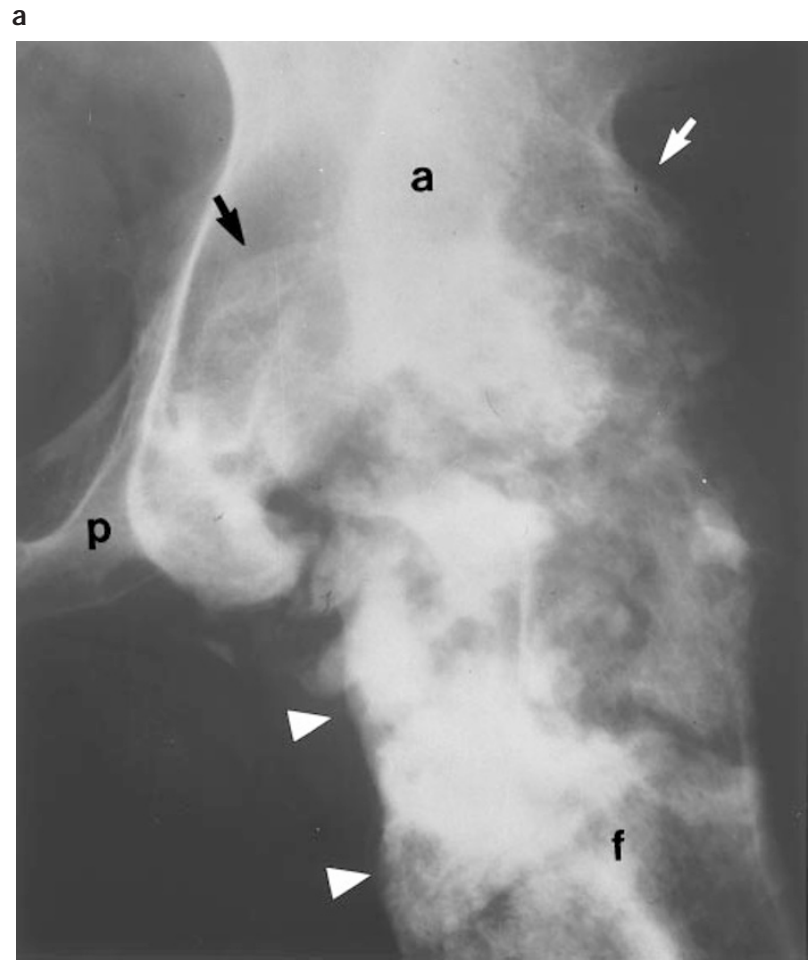

b
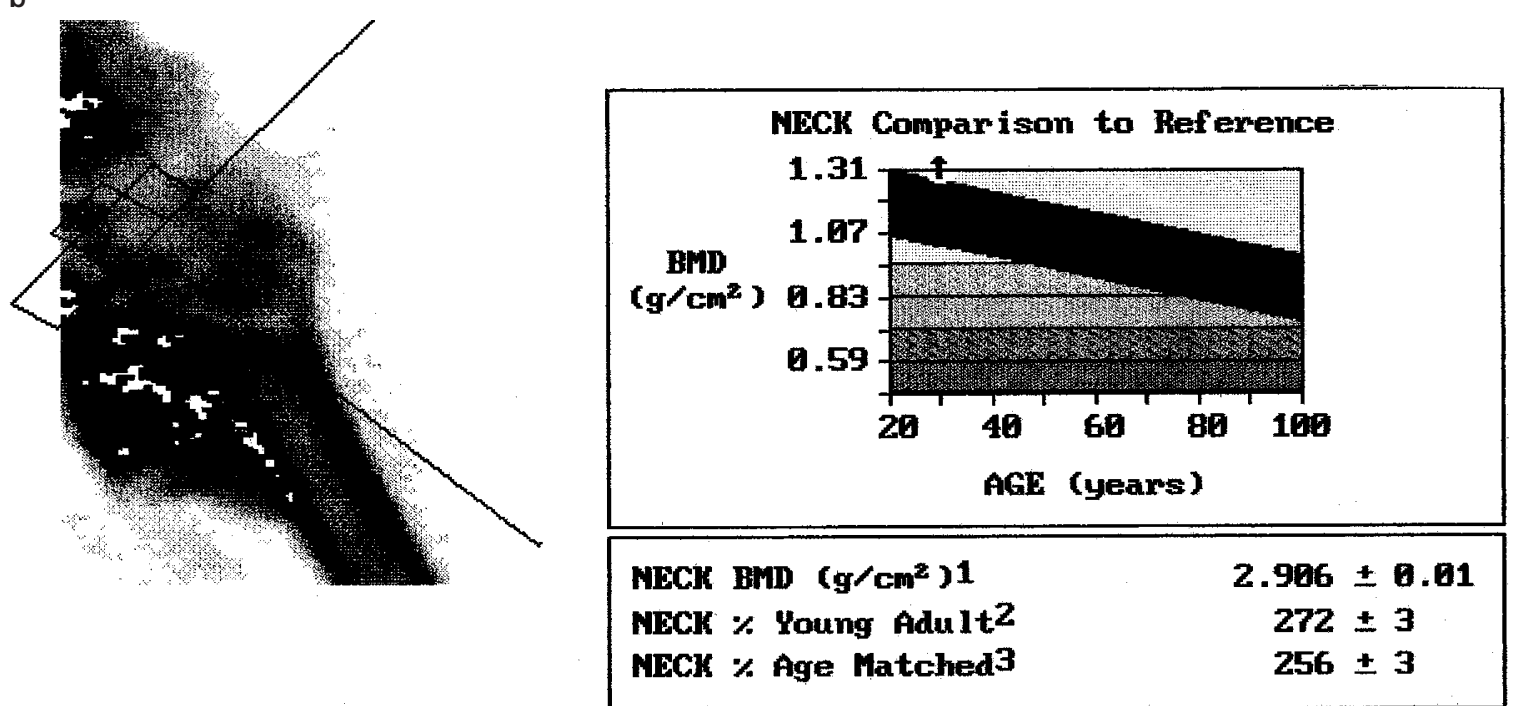

Figure 1 (a) Radiograph of the left hip in a 30-year-old male patient reveals extensive radiodense heterotopic ossification overlying the acetabulum (arrows) and extending downward to overlie the proximal femoral region (white arrowheads). a = acetabulum, $\mathrm{p}=$ pubic ramus, $\mathrm{f}=$ proximal femur. (b) Bone densitometry results reveal markedly elevated BMD of all ROIs of the hip: the femoral neck, Ward's triangle, and the trochanteric region $\left(2.91,2.77\right.$, and $1.47 \mathrm{~g} / \mathrm{cm}^{2}$, respectively) 
The statistical results were as follows: (1) When the data was stratified by each patient, there was no statistically significant elevation of bone densitometric values of all studied parameters (BMC, BMD, percentage of BMD compared to age-matched controls) in the group of patients with HO compared to the group without $\mathrm{HO}$ and to the entire study population; (2) When the data was stratified by each ROI, we found statistically significant elevation of bone densitometric values in all ROIs of the hip in the

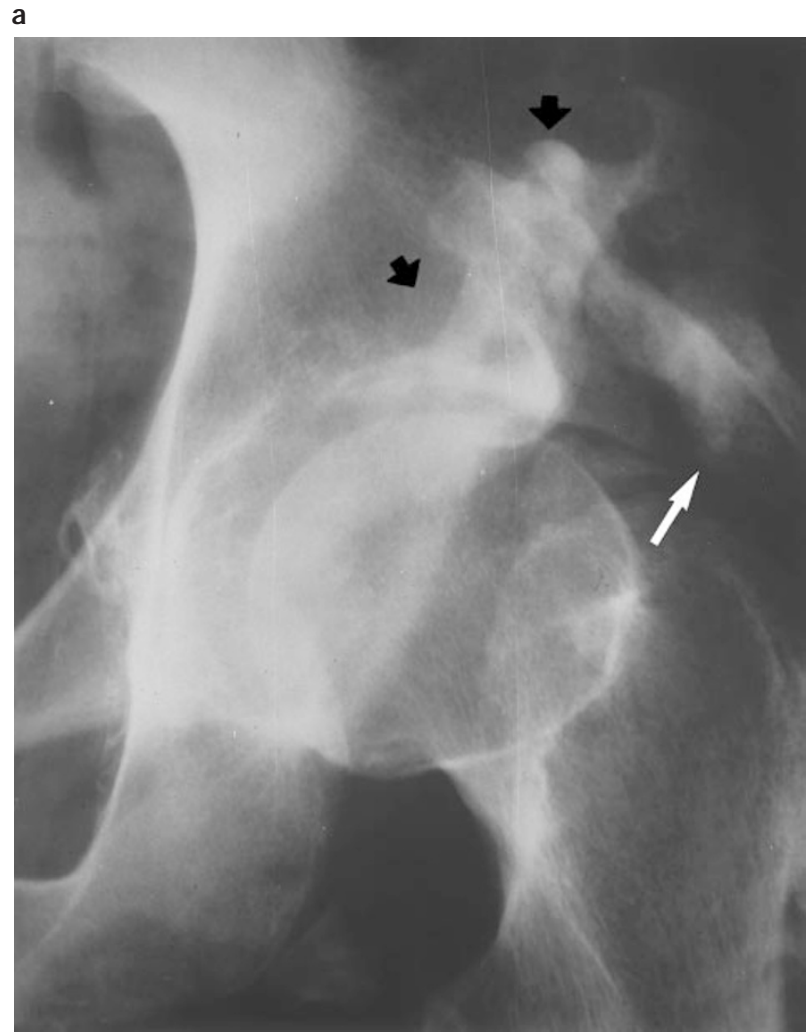

b
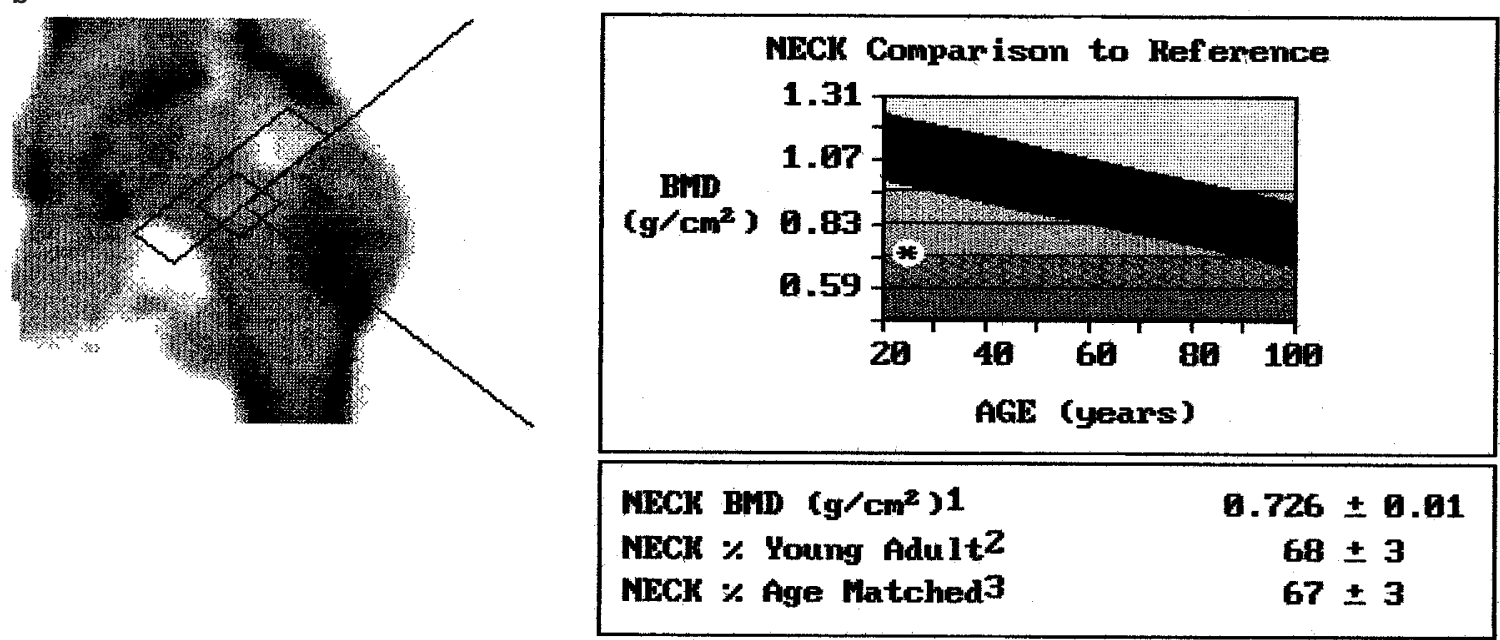

Figure 2 (a) Radiograph of the left hip in a 25-year-old male patient reveals radiodense deposits of a considerable size overlying the acetabulum (black arrows) and proximal femur (white arrow). Its internal trabecular pattern indicates bone formation. All ROIs of the hip are affected. (b) The bone density results disclose the lower-than-average BMD of the femoral neck $\left(0.73 \pm 0.02 \mathrm{~g} / \mathrm{cm}^{2}\right)$. The BMD of Ward's triangle and the trochanteric region are 0.61 and $1.01 \mathrm{~g} / \mathrm{cm}^{2}$, respectively. The BMD results are decreased in spite of overlying HO, suggesting that the fracture risk of this patient is underestimated, and is actually higher. (Owing to some limitations in patient's positioning, the ROIs were manually adjusted) 
patients with $\mathrm{HO}$ compared to the group without $\mathrm{HO}$ and to the entire study population as follows: (a) At the femoral neck; the BMC was elevated by 29; (b) At Ward's triangle; the BMC was elevated by $89-101 \%$ and the percentage of BMD compared to age-matched control by $39-43 \%$ (c) At the trochanter; the BMC was elevated by $35-43 \%$, and the BMD by $21 \%$ (Table 1; Figures 1-3).

The prevalence of $\mathrm{HO}$ was high (14 of 19 patients $=73 \%$ ) when age of patients at injury were in the range of 20-39 years (Table 2). Prevalence of HO was not much different when grouping the patients with $\mathrm{HO}$ by age of injury (time since event Table 3) and by age of patients when the DEXA was taken (patients' present age - Table 4). What we have observed was when age of injury (time since event) was between 20-29 years all ROIs of the hip were affected, referring that BMD or proximal femur in SCI patients was $8-13 \%$ lower than age matched controls. $6,13-15$ Because the number of patients with $\mathrm{HO}$ and number

a

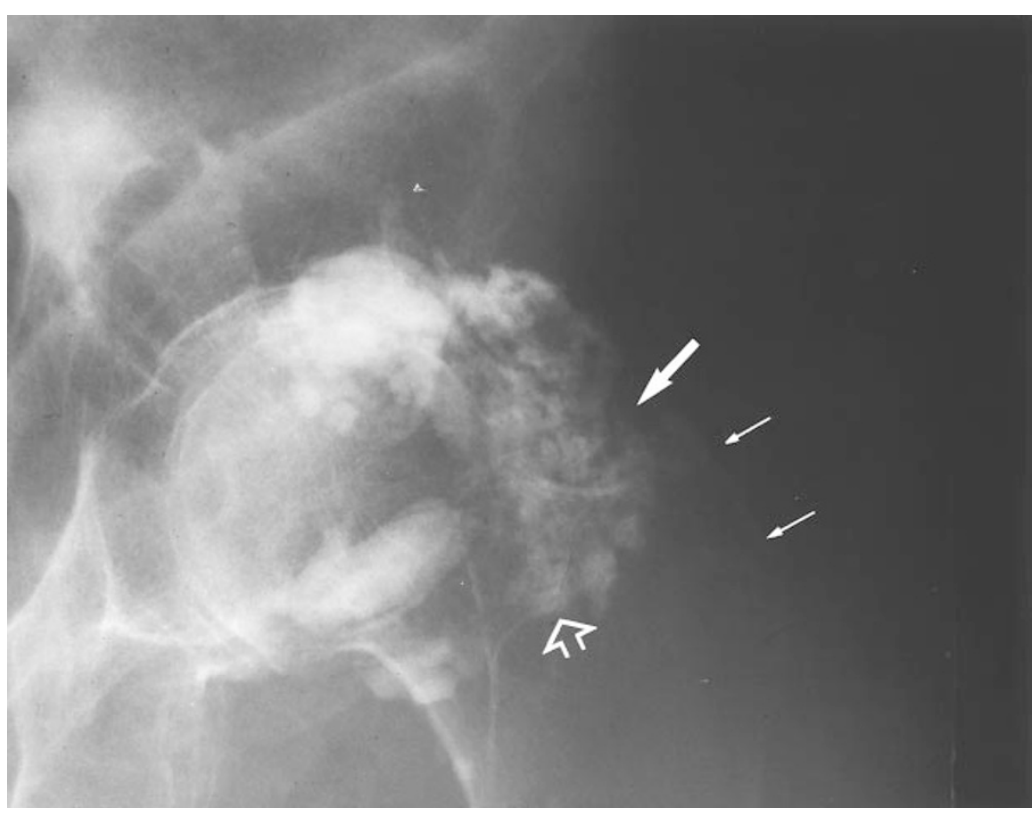

b

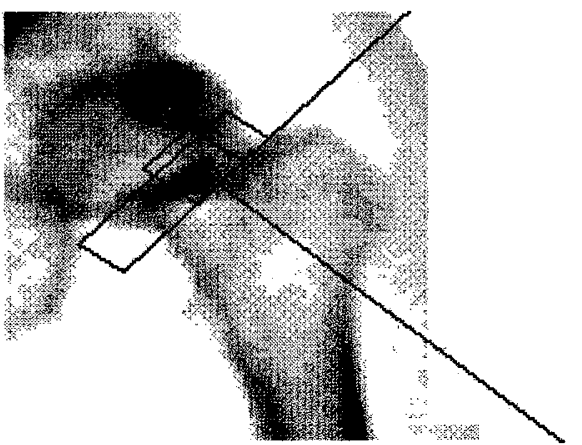

NECK Comparison to Reference

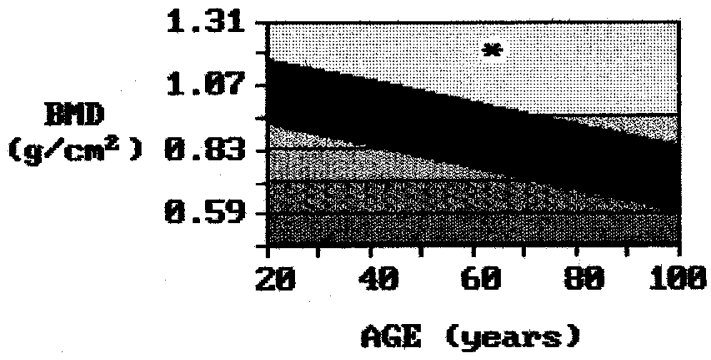

\begin{tabular}{|lc|}
\hline \hline NECK BMD $\left(g / \mathrm{cm}^{2}\right) 1$ & $1.200 \pm 0.62$ \\
NECK \% Young Adult' & $112 \pm 3$ \\
NECK \% Age Matched & $139 \pm 3$ \\
\hline
\end{tabular}

Figure 3 (a) Radiograph of the left hip in a 64-year-old male patient reveals heterotopic ossification overlying the femoral neck (arrow) and Ward's triangle (hallow arrow). The tronchanteric region is relatively preserved (thin arrows). (b) From the bone density results, the BMDs of the femoral neck, Ward's triangle, and the trochateric region are $1.20,1.18$, and $0.58 \mathrm{~g} / \mathrm{cm}^{2}$, respectively. In this particular case, the BMD of the trochanteric region is relatively most reliable. (Owing to some limitations in patient's positioning, the ROIs were manually adjusted) 
of age-matched controls were small (controls that were matched for age of patients at injury, age of injury, and age of patients when the DEXA was taken), it was insufficient to do statistical analysis.

\section{Discussion}

Heterotopic ossification (HO) is reported most commonly in association with paraplegia secondary to spinal cord trauma in which it may be observed in $16-53 \%$ of cases, ${ }^{5,10,11,16-18}$ and the hip is the most commonly affected region. ${ }^{8-11,19}$ In our study, we found the prevalence of $\mathrm{HO}$ to be $18 \%$ corresponding to this range. In SCI patients, $\mathrm{HO}$ has some particular characters. It has been observed to be present as early as 18 days after SCI, ${ }^{10}$ which is earlier than the time period of 1-6 months after other injuries. ${ }^{9,10}$ It is more common after injury of the lower cervical or thoracic spine than after those of lumbar spine ${ }^{8}$ and it occurs in both flaccid and spastic forms of paralysis. Although ossification is almost always seen in a paraplegic limb or limbs, this association is not constant. ${ }^{5}$

Table 2 Number of patients with $\mathrm{HO}$ and average percentage of BMD of proximal femur compared with agematched controls, when grouped by age of patients at the time of injury

\begin{tabular}{|c|c|c|c|}
\hline $\begin{array}{l}\text { Age of patients at } \\
\text { injury }{ }^{a} \text { (years) }\end{array}$ & \multicolumn{3}{|c|}{$\begin{array}{c}\text { Average percentage } \\
\text { of BMD of proximal femur } \\
\text { compared to age-matched controls } \\
\text { Neck } \quad \text { Ward's Trochanter }\end{array}$} \\
\hline$<20$ years $\quad(1)^{\mathrm{b}}$ & 176.0 & 177.0 & 190.0 \\
\hline $20-39$ years (14) & 80.0 & 85.9 & 81.9 \\
\hline $40-59$ years (2) & 69.0 & 62.0 & 66.0 \\
\hline$\geqslant 60$ years & 100.0 & 97.5 & 92.5 \\
\hline
\end{tabular}

${ }^{\mathrm{a}}$ The mean age of these 19 patients at the time of injury $=31.1 \pm 15.9$ years with standard error of the mean \pm 3.7 years. ${ }^{b}$ In brackets are number of patients

Table 3 Number of patients with $\mathrm{HO}$ and average percentage of BMD of proximal femur compared with agematched controls, when grouped by age of injury (time since event)

\begin{tabular}{|c|c|c|c|c|}
\hline \multicolumn{2}{|l|}{$\begin{array}{l}\text { Age of injury }{ }^{a} \\
\text { (years) }\end{array}$} & \multicolumn{3}{|c|}{$\begin{array}{c}\text { Average percentage } \\
\text { of BMD of proximal femur } \\
\text { compared to age-matched controls }\end{array}$} \\
\hline$<20$ years & $(7)^{b}$ & 84.4 & 83.0 & 88.6 \\
\hline $10-19$ years & (2) & 64.0 & 66.0 & 66.0 \\
\hline $20-29$ years & (5) & 94.0 & 91.8 & 107.8 \\
\hline $30-39$ years & (4) & 89.2 & 100.0 & 69.0 \\
\hline $40-49$ years & (1) & 88.0 & 126.0 & 86.0 \\
\hline
\end{tabular}

We had already conducted a study concerning the patterns of spinal cord injury associated bone loss (SABL) on this same group of patients using ablebodied individuals (age-matched controls) ${ }^{12}$ and found that the BMDs of our patients in the proximal femoral regions were $8-13 \%$ lower than age-matched controls. These findings corresponded to those of many authors. ${ }^{6,13-15}$ Stewart et al. ${ }^{20}$ reported two cases of SCI patients having elevated hip densitometry secondary to adjacent $\mathrm{HO}$, and stated that clinical and radiographic correlation was necessary in densitometric determination. However, the numbers in their study population were small. We performed this densitometric study using substantial numbers of patients to determine the magnitude of influence of $\mathrm{HO}$ on results. We found that multiple measured parameters at all three ROIs of the hip had statistically significantly false elevation secondary to the overlying $\mathrm{HO}$, indicating that the lower BMDs found in our previous study, ${ }^{12}$ and probably in other studies, were actually underestimated and that the true risk of fracture was resultingly higher. The elevation was most dramatic in the BMC of Ward's triangle compared to both patients without HO (101\%; $P<0.001)$ and to the entire study population $(89 \%$; $P<0.001)$. These recent findings therefore not only provide insight into our previous study, ${ }^{12}$ but also establish the significant influence of $\mathrm{HO}$ on proximal femoral densitometry. Interestingly, $\mathrm{HO}$ at the femoral neck was more commonly observed compared to other ROIs of the hip, but showed the least statistical significance [only the femoral neck BMC was significantly elevated $(29 \% ; \quad P<0.05)]$. We have observed that in patients with $\mathrm{HO}$, the bone densitometry will sometimes show the irregular areas of ossification, and plain radiography should be requested for confirmation.

Certain study limitations should be acknowledged. The first shortcoming is the type and sex bias in our study population. HO was reported to occur most commonly in SCI patients ${ }^{5,10,11}$ and in males more than

Table 4 Number of patients with $\mathrm{HO}$ and average percentage of BMD of proximal femur compared with agematched controls, when grouped by age of patients when DEXA was taken (patients' present age)

\begin{tabular}{|c|c|c|c|}
\hline \multirow{2}{*}{$\begin{array}{l}\text { Age of patients when } \\
\text { DEXA was taken } \\
\text { (years) }\end{array}$} & \multicolumn{3}{|c|}{$\begin{array}{c}\text { Average percentage } \\
\text { of BMD of proximal femur } \\
\text { compared to age-matched } \\
\text { controls }\end{array}$} \\
\hline & Neck & Ward's & Trochanter \\
\hline$<20$ years & - & - & - \\
\hline $20-39$ years & 76.2 & 78.8 & 87.0 \\
\hline $40-59$ years $(8)$ & 89.9 & 89.9 & 92.9 \\
\hline$\geqslant 60$ years & 89.0 & 100.2 & 79.2 \\
\hline
\end{tabular}

${ }^{\text {a }}$ The mean age of these 19 patients at the time DEXA was taken $=50.9 \pm 14.4$ years with standard error of the mean \pm 3.3 years. ${ }^{b}$ In brackets are number of patients 
twice as often as females $(23 \%: 10 \%) .{ }^{8}$ Since our entire study population included male SCI patients, the incidence of $\mathrm{HO}$ was higher than it might have been without a sex bias. The second limitation is the number of patients with HO (19 patients $=18 \%)$ in this study. Although it corresponded to the previously described range and showed statistically significant influence on the densitometric values, the number is rather small. Third, we used plain radiographs to diagnose HO. It is well recognized that the elevation of alkaline phosphatase and the clinical manifestations of HO can precede the abnormal radiograph ${ }^{9,21}$ from 1 week to 4 months and from 2-4 weeks ${ }^{9}$ respectively, and skeletal scintigram was also reported to be more sensitive than radiography in this respect. ${ }^{9,16,17,22,23}$ Radiography is therefore not the most sensitive modality for diagnosing HO. But whether the elevated alkaline phosphatase, the positive clinical signs, and the positive scintigram without radiographically demonstrable $\mathrm{HO}$ influence bone densitometric values is not yet known. Accordingly, $\mathrm{HO}$ when radiographically demonstrated, is definite. However, all of 19 patients with $\mathrm{HO}$ in this study had normal alkaline phosphatase from laboratory studies.

In conclusion, HO involving the hip can cause various magnitudes of significantly elevated bone densitometric values at each three ROI; ranging from $29-101 \%$ for BMC, $21 \%$ for BMD, and $39-43 \%$ for percentage of BMD compared to age-matched controls. The prevalence of $\mathrm{HO}$ was observed to be high when age of patients at injury were in the range of 20-39 years. When HO occurs, it can obscure underlying osteoporosis, leading to misinterpretation and underestimation of fracture risk. The lower proximal femoral BMD recognized in SCI patients as compared to age-matched controls is probably much lower in these studies which have not been corrected for this phenomenon. Observation of irregular areas of ossification on bone densitometry of the hip should arise the possibility of $\mathrm{HO}$, and corresponding plain radiographs should be requested for confirmation. Recognition of this phenomenon will be helpful in management of patients at risk of $\mathrm{HO}$, particularly SCI patients.

\section{Acknowledgements}

This work was supported in part by the American Paralysis Association.

\section{References}

1 Sartoris DJ. Coding and reimbursement issues for dual-energy X-ray absorptiometry. AJR Am J Roentgenol 1994; 163: $137-$ 139.

2 Hughes TH, Yu JS, Sartoris DJ. Imaging of osteoporosis. J South Orthop Assoc 1993; 2: 173 - 184.

3 Garland DE et al. Osteoporosis after spinal cord injury. J Orthop Res 1992; 10: 371 - 378 .

4 Carter DR, Bouxsein ML, Marcus R. New approaches for interpreting projected bone densitometry data. J Bone Miner Res 1992; 7: $137-145$.

5 Resnick D. Neuromuscular disorders. In: Resnick D (ed). Diagnosis of Bone and Joint Disorders. 3rd edn. WB Saunders: Philadelphia, 1995, pp 3365-3406.

6 Leslie WD, Nance PW. Dissociated hip and spine demineralization: A specific findings in spinal cord injury. Arch Phys Med Rehabil 1993; 74: 960-964.

7 Sugarman B. Medical complications of spinal cord injury. $Q J$ Med 1985; 54: 3 - 18

8 Wittenberg RH, Peschke U, Botel U. Heterotopic ossification after spinal cord injury. J Bone Joint Surg 1992; 74-B: 215-218.

9 Tibone $\mathbf{J}$ et al. Heterotropic ossification around the hip in spinal cord-injured patients. J Bone Joint Surg 1978; 60-A: 769.

10 Lal S, Hamilton BB, Heinemann A, Betts HB. Risk factors for heterotopic ossification in spinal cord injury. Arch Phys Med Rehabil 1989; 70: $387-390$.

11 Hassard GH. Heterotopic bone formation about the hip and unilateral decubitus ulcers in spinal cord injury. Arch Phys Med Rehabil 1975; 56: $355-358$.

12 Szollar SM, Martin EME, Parthemore JG, Sartosis DJ, Deftos LJ. Patterns of spinal cord injury associated bone loss (SABL). Spinal Cord 1997; 35: 223-228.

13 Biering-Sorensen F, Bohr H, Schaadt O. Bone mineral content of the lumbar spine and lower extremities years after spinal cord lesions. Paraplegia 1988; 26: $293-301$.

14 Biering-Sorensen F, Bohr HH, Schaadt OP. Longitudinal study of bone mineral content in the lumbar spine, the forearm and the lower extremities after spinal cord injury. Eur J Clin Invest 1990; 20: 330 - 335

15 Sharp CA, Inman C, Worsfold M, Ristelli J, Davis MWJ. Bone turnover after spinal cord injury. Bone 1995; 16: 1865S.

$16 \mathrm{Hsu}$ JD, Sakimura I, Stauffer ES. Heterotopic ossification around the hip joint in spinal cord injured patients. Clin Orthop Rel Res 1975; 112: 165.

17 Finerman GAM, Stover SL. Heterotopic ossification following hip replacement or spinal cord injury. Two clinical studies with EHDP. Metab Bone Dis Rel Res 1981; 4: 337-342.

18 Colachis SC, Clinchot DM, Venesy D. Neurovascular complications of heterotopic ossification following spinal cord injury. Paraplegia 1993; 31: $51-57$.

19 Bravo-Payno P, Esclarin A, Arzoz T, Arroyo O, Labarta C. Incidence and risk factors in the appearance of heterotopic ossification in spinal cord injury. Paraplegia 1992; 30: 740-745.

20 Stewart CA, Hung GL, Garland DE, Rosen CD, Adkins R. Heterotopic ossification. Effect on dual-photon absorptiometry. Clin Nucl Med 1990; 15: 697-700.

21 Nicholas JJ. Ectopic bone formation in patients with spinal cord injury. Arch Phys Med Rehabil 1973; 54: 354-359.

22 Prakash V. Radionuclide assessment of heterotopic ossification in spinal cord injury patients. J Am Paraplegia Soc 1983; 6: $10-$ 12.

23 Kim SW, Wu SY, Kim RC. Computerized quantitative radionuclide assessment of heterotopic ossification in spinal cord injury patients. Paraplegia 1992; 30: 803-807. 